\title{
Molecular and immunohistochemical analyses of the focal form of congenital hyperinsulinism
}

\author{
Mariko Suchi ${ }^{1}$, Courtney M MacMullen², Paul S Thornton ${ }^{2, *}$, N Scott Adzick ${ }^{3}$, \\ Arupa Ganguly ${ }^{4}$ Eduardo D Ruchelli ${ }^{1}$ and Charles A Stanley ${ }^{2}$ \\ ${ }^{1}$ Department of Pathology and Laboratory Medicine, The Childrens' Hospital of Philadelphia and University \\ of Pennsylvania School of Medicine, Philadelphia, PA, USA; ${ }^{2}$ Division of Endocrinology, Department of \\ Pediatrics, The Childrens' Hospital of Philadelphia and University of Pennsylvania School of Medicine, \\ Philadelphia, PA, USA; ${ }^{3}$ Department of Surgery, The Childrens' Hospital of Philadelphia and University \\ of Pennsylvania School of Medicine, Philadelphia, PA, USA and ${ }^{4}$ Department of Genetics, University of \\ Pennsylvania School of Medicine, Philadelphia, PA, USA
}

\begin{abstract}
Congenital hyperinsulinism is a rare pancreatic endocrine cell disorder that has been categorized histologically into diffuse and focal forms. In focal hyperinsulinism, the pancreas contains a focus of endocrine cell adenomatous hyperplasia, and the patients have been reported to possess paternally inherited mutations of the $A B C C 8$ and $K C N J 11$ genes, which encode subunits of an ATP-sensitive potassium channel $\left(\mathrm{K}_{\mathrm{ATP}}\right)$. In addition, the hyperplastic endocrine cells show loss of maternal $11 p 15$, where imprinted genes such as $p 57^{\text {kip } 2}$ reside. In order to evaluate whether all cases of focal hyperinsulinism are caused by this mechanism, 56 pancreatectomy specimens with focal hyperinsulinism were tested for the loss of maternal allele by two methods:

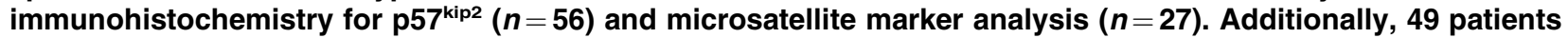
were analyzed for $K_{A T P}$ mutations. Out of 56 focal lesions, 48 demonstrated clear loss of $\mathrm{p} 57^{\mathrm{kip} 2}$ expression by immunohistochemistry. The other eight lesions similarly showed no nuclear labeling, but the available tissue was not ideal for definitive interpretation. Five of these eight patients had paternal $\mathrm{K}_{\text {ATP }}$ mutations, of which four demonstrated loss of maternal 11p15 within the lesion by microsatellite marker analysis. All of the other three without a paternal $K_{A T P}$ mutation showed loss of maternal 11p15. $K_{A T P}$ mutation analysis identified $32 / 49$ cases with paternal mutations. There were seven patients with nonmaternal mutations whose paternal DNA material was not available, and one patient with a mutation that was not present in either parent's DNA. These eight patients showed either loss of $\mathrm{p} 57^{\mathrm{kip} 2}$ expression or loss of maternal $11 \mathrm{p} 15$ region by microsatellite marker analysis, as did the remaining nine patients with no identifiable $K_{A T P}$ coding region mutations. The combined results from the immunohistochemical and molecular methods indicate that maternal 11p15 loss together with paternal $\mathrm{K}_{\mathrm{ATP}}$ mutation is the predominant causative mechanism of focal hyperinsulinism. Modern Pathology (2006) 19, 122-129. doi:10.1038/modpathol.3800497
\end{abstract}

Keywords: congenital hyperinsulinism; ATP-sensitive potassium channel; adenomatous hyperplasia; loss of heterozygosity; p57 ${ }^{\mathrm{kip} 2}$; nesidioblastosis

Infants with congenital hyperinsulinism were once believed to have abnormal pancreatic development associated with persistence of packets of islet cells budding off ducts, termed nesidioblastosis. ${ }^{1}$ Observations based on immunohistochemical investigations have shown that nesidioblastosis, as defined

Correspondence: $\mathrm{Dr}$ M Suchi, MD, PhD. Current address: Department of Pathology, Children's Hospital of Wisconsin, 9000 West Wisconsin Avenue, Milwaukee, WI 53226, USA.

E-mail: msuchi@mcw.edu

${ }^{*}$ Current address: Endocrinology, Cook Children's Health System, Fort Worth, TX, USA

Received 31 May 2005; revised 22 August 2005; accepted 26 August 2005 above, is a common feature of the pancreas in normoglycemic neonates and infants, ${ }^{2-4}$ and nesidioblastosis by itself is not considered the underlying histologic basis of congenital hyperinsulinism. Recent studies on the molecular basis of the disease have disclosed specific genetic defects in the regulation of insulin secretion. ${ }^{5}$ Patients with mutations in glucokinase (GK, MIM.138079), ${ }^{6}$ glutamate dehydrogenase (GLUD1, MIM.138130), ${ }^{7}$ and shortchain L-3-hydroxyacyl coenzyme A dehydrogenase (SAHAD, MIM 601609) ${ }^{8}$ usually respond to medical therapy with diazoxide. The most severe form of hyperinsulinism unresponsive to diazoxide is presumed to be associated with defects in a $\beta$-cell ATP-sensitive potassium channel, $\mathrm{K}_{\mathrm{ATP}}{ }^{9,10}$ because 
diazoxide suppresses insulin release through its action at the $\mathrm{K}_{\mathrm{ATP}}$. The $\mathrm{K}_{\mathrm{ATP}}$ is a hetero-octamer composed of two subunits encoded by two separate genes, ABCC8 (formerly SUR1, MIM.600509) and KCNJ11 (formerly Kir6.2, MIM.600937) that reside on the same locus of chromosome 11p15.

Two histologically and genetically distinct groups are recognized among patients with $\mathrm{K}_{\mathrm{ATP}}$ defects, diffuse hyperinsulinism and focal hyperinsulinism. ${ }^{11}$ Diffuse hyperinsulinism is characterized by the presence of enlarged islet cell nuclei throughout the pancreas, and is due to recessive mutations in $A B C C 8^{12,13}$ or $K C N J 11 .^{14,15}$ All $\beta$ cells are functionally abnormal, and infants with diffuse hyperinsulinism require near total pancreatectomy to achieve control over blood sugar levels. Focal hyperinsulinism, on the contrary, can be cured by resection of a focus of adenomatous hyperplasia (Figure 1a and b). ${ }^{16,17}$ The lesion is present within an otherwise normal pancreas with islet cell nuclei of normal size.

The focal type of congenital hyperinsulinism has been demonstrated to arise in individuals who have a germline mutation in the paternal allele of $A B C C 8$ or KCNJ11. Focal proliferation of $\beta$ cells occurs when there is a somatic loss of the maternally derived 11p15 in one of the $\beta$ cells. ${ }^{18,19}$ The acquired event results in expression of the mutated paternal allele, and thereby a functional loss of the $\mathrm{K}_{\mathrm{ATP}}$. In the sub-band harboring the ABCC8 and KCNJ11 loci, there are imprinted genes whose products are involved in regulation of cell proliferation, such as H19, p57 ${ }^{\text {kip2 }}$, and IGF2. ${ }^{20-22} \mathrm{H} 19$ and p57 ${ }^{\text {kip2 }}$ are expressed on the maternal allele, whereas IGF2 is expressed on the paternal allele. p5 $7^{\mathrm{kip} 2}$ has been shown to lead to cell cycle arrest by acting as an inhibitor of G1 cyclin/cyclin-dependent kinase complexes. ${ }^{23,24}$ p57 $7^{\text {kip } 2}$ expression is demonstrated in the pancreatic endocrine cells, and the fraction of $\beta$ cells expressing p57 ${ }^{\text {kip2 }}$ does not vary during development. ${ }^{25}$ While dysregulation of insulin secretion by $\beta$ cells results from the abnormal $\mathrm{K}_{\mathrm{ATP}}$ activity, it has been hypothesized that the endocrine cell proliferation that characterizes focal hyperinsulinism is due to an imbalance of the imprinted genes located at $11 \mathrm{p} 15$.

Screening and sequencing of ABCC8 and KCNJ11 genes have identified more than 40 mutations causing congenital hyperinsulinism. No 'hot spots' for mutations are present; most mutations are unique to the respective family, except for two mutations common in the Ashkenazi Jewish population. ${ }^{15}$ In the focal form of hyperinsulinism, our results and those of others are consistent and demonstrate that coding region mutations in the paternal allele are identified in $60-70 \%$ of the patients. ${ }^{26}$ Since $\mathrm{K}_{\mathrm{ATP}}$ mutations have not always been identified in patients with the histologically focal form, we questioned whether all cases of focal hyperinsulinism are caused by the same mechanism.

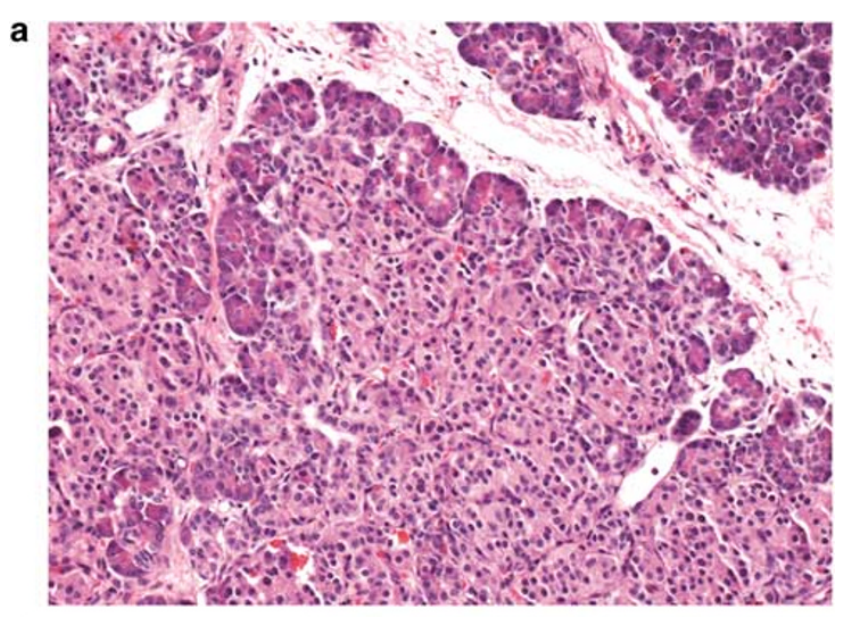

b
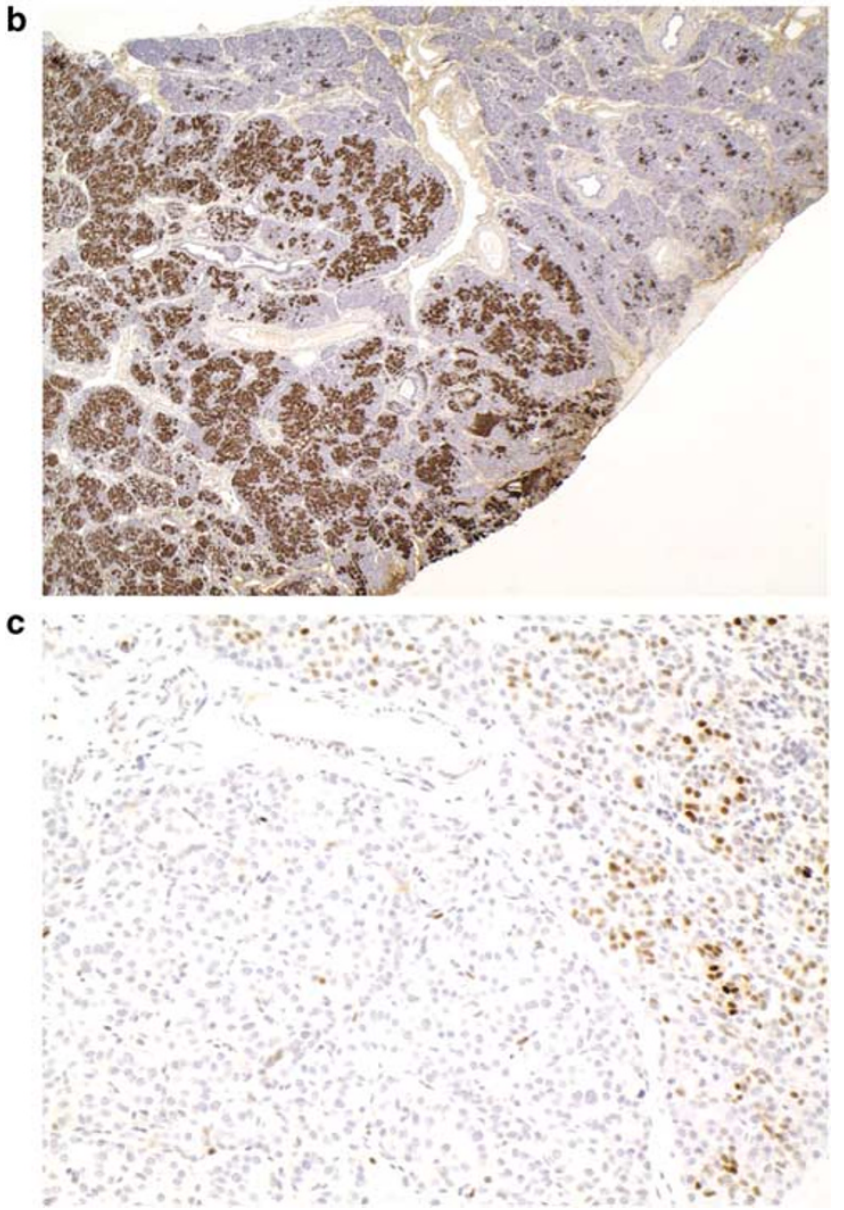

Figure 1 Photomicrographs of the focal form of congenital hyperinsulinism, case no. 19. (a) Endocrine cells occupy more than $40 \%$ of lobules in a focus of adenomatous hyperplasia (focal hyperinsulinism). Hematoxylin and eosin, original magnification $\times 200$. (b) Immunohistochemistry for insulin, original magnification $\times 20$. (c) Immunohistochemistry for $\mathrm{p}^{\mathrm{kip} 2}$, original magnification $\times 200$. Endocrine cell nuclei within the focus of adenomatous hyperplasia are negative for $\mathrm{p} 57^{\mathrm{kip} 2}$, while islet cell nuclei in the normal area of the pancreas are positive. A small number of duct epithelial cells and acinar cells also show positive labeling.

In order to answer this question, 56 pancreatectomy specimens with a focal lesion were analyzed. We used immunohistochemistry for $\mathrm{p} 57^{\mathrm{kip} 2}$ to 
demonstrate loss of gene expression on the maternal allele $^{27}$ and microsatellite marker analysis to document directly the loss of maternal 11 p15 region in pancreata with focal lesions.

\section{Materials and methods}

\section{Patients}

A total of 125 children underwent partial or neartotal pancreatectomy for treatment of congenital hyperinsulinism at the Children's Hospital of Philadelphia between January 1, 1990 and May 31 , 2004. In children who had pancreatectomy after October 1, 1998 (101 cases), intraoperative frozen section analysis was performed to guide the extent of surgery. ${ }^{17}$ The pancreatic specimens were subsequently routinely processed, and, using previously described criteria, ${ }^{28}$ one of the following diagnoses was assigned: diffuse hyperinsulinism, focal hyperinsulinism, or equivocal (when histologic features did not meet the criteria). In all, 57 patients were identified to have the focal form, but one case was excluded from the study because the focus of adenomatous hyperplasia was exhausted during additional sectioning of the paraffin-embedded tissue. Age at the time of initial surgery ranged from 13 to 431 days (mean $=96$ days). Long-term follow-up information (at least 10 months post-surgery) including formal evaluation of fasting adaptation was available for 31 patients. Thirteen patients were cured, 12 were adequately controlled, and six remained hypoglycemic, including four who underwent additional surgery. Terms to describe the outcome (cure and adequate control) have been defined previously. ${ }^{17}$ Short-term informal postoperative outcome information was available in 16 patients. Seven patients were cured, eight became medically manageable, but one patient remained hypoglycemic and underwent an additional pancreatic resection. Written informed consent was obtained from parents of the children. The study was approved by the Children's Hospital of Philadelphia institutional review board.

\section{Immunohistochemistry}

Formalin-fixed, paraffin-embedded tissue blocks were sectioned at a thickness of $5 \mu \mathrm{m}$ and were placed on Superfrost Plus (silanated) slides (Fisher, Pittsburgh, PA, USA). They were heated at $60^{\circ} \mathrm{C}$ for $20 \mathrm{~min}$, deparaffinized in xylene, and hydrated in a graded series of alcohols. Immunohistochemistry for p5 $7^{\text {kip2 }}$ was performed with an avidin-biotin horseradish peroxidase complex system using the Vectastain Elite ABC kit (PK-6100, Vector Laboratories, Burlingame, CA, USA), diaminobenzidine tetrahydrochloride (Dako, Carpinteria, CA, USA), and Dako Autostainer Universal Staining System with hema- toxylin as counterstain. Primary mouse monoclonal antibody, p57 kip2 Ab-6 (Lab Vision Corporation, Fremont, CA, USA), secondary biotinylated antiguinea-pig IgG (BA700, Vector laboratories, Burlingame, CA, USA), and normal goat serum (S1000, Vector Laboratories, Burlingame, CA, USA) were used. Antigen retrieval was carried out using a microwave oven. Negative controls consisted of substitutions of buffer for the primary antibody. Nuclear labeling of the lesional islet cells and the islet cells in the surrounding normal pancreas was recorded. When the nuclear counter stain by hematoxylin was completely obscured by the reaction (brown color), the reaction was interpreted as strong. When the counter stain could still be seen, the reaction was interpreted as moderate. When there was only faint or equivocal brown color on the nuclei, the reaction was interpreted as weak. Pancreatic tissue obtained from a normoglycemic individual was used to compare the labeling intensity among separate runs. For comparison, immunohistochemistry for p57 $7^{\text {kip2 }}$ was also performed on 10 cases with the diffuse form of congenital hyperinsulinism.

\section{$\mathrm{K}_{\mathrm{ATP}}$ Mutation Analysis and Microsatellite Haplotype Analysis}

Genomic DNA from patients and their parents was isolated from $3 \mathrm{ml}$ of peripheral blood using the PUREGENE blood kit (Gentra Systems, Minneapolis, MN, USA). Mutations for ABCC8 and KCNJ11 genes were screened and identified by conformationsensitive gel electrophoresis and by direct sequencing as described previously. ${ }^{28,29}$ Paraffin-embedded blocks containing a focus of adenomatous hyperplasia and unaffected pancreas were selected for each case. The tissue was sectioned at a thickness of $4-5 \mu \mathrm{m}$, and was placed on Superfrost Plus (silanated) slides (Fisher, Pittsburgh, PA, USA). On average, 10-15 sections from the lesional areas and normal areas were prepared. DNA was extracted from both areas with the PUREGENE Cell and Tissue kit (Gentra Systems, Minneapolis, MN, USA). Patient and parent genomic DNA from leukocytes, patient lesional tissue DNA, and patient normal tissue DNA were amplified for microsatellite markers (D11S909, D11S921, D11S902, and D11S899) using fluorescent labeled forward primers and True Allele PCR Premix (Perkin-Elmer, Boston, MA, USA). All these markers lie on chromosome 11p flanking the $A B C C 8 / K C N J 11$ locus. The primer sequences for these markers were obtained from the Genome Database website (http://www.gdb.org/). Additional 4 base pair (GAAA) $n$ and 2 base pair (CA) $n$ repeats were chosen from intron 7 and intron 10, respectively, of the ABCC8 gene. Primer sequences were $5^{\prime}$ GCGACACAGCAAGACTCTG-3' and 5'-CTCCCTA ACTCCTTTCTTT- $3^{\prime}$ for the intron 7 repeat, and $5^{\prime}$ - 


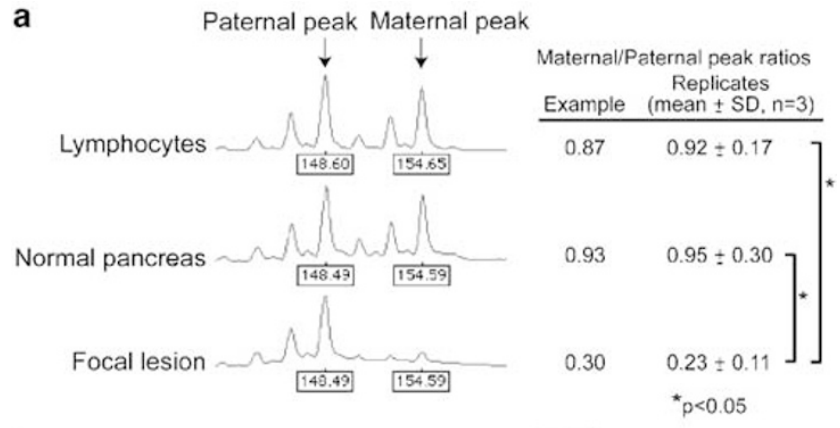

b

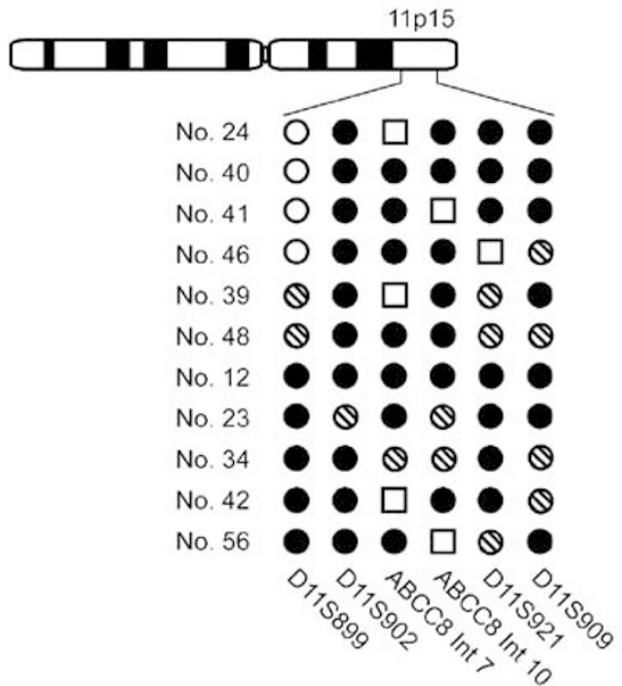

Figure $211 \mathrm{p} 15$ microsatellite marker analysis. (a) Microsatellite marker, $A B C C 8$ intron 10, patterns in patient no. 19, showing loss of the maternal $154 \mathrm{bp}$ allele in DNA from the focal lesion compared to lymphocytes or adjacent normal pancreas. (b) Representative focal lesions showing loss of maternal 11p15, including two cases with no identifiable mutation (nos. 42 and 46) and a case with a de novo mutation (no. 40). Solid black circles represent maternal allelic loss. Open circles represent no significant allelic loss. Shaded circles represent uninformative markers. Open squares represent failure of PCR amplification.

GCTTTTGACACAACAGGAAGAT-3'and 5'-GGCTG GGAGAGTAGAATCATCAG-3' for the intron 10 repeat. The PCR products were run on an ABI 377 sequencer and analyzed using the ABI Prism Genescan3.0 (Perkin-Elmer, Boston, MA, USA) and ABI Prism Genotyper2.1 (Perkin-Elmer, Boston, MA, USA) software to determine the peak sizes and peak areas for the specific marker allele. The ratio of the maternal to paternal peak areas for the lesion was compared to the same ratio for the peaks from the normal pancreatic tissue (or lymphocytes, if normal tissue was limited in quantity), as shown in Figure 2a. Each marker was run at least in triplicate and the ratios for normal and lesional tissue were compared using the Student's $t$-test. The maternal allele was deemed lost when the focal lesion ratio was less than the normal tissue ratio, with $P<0.05$ considered as significant.

\section{Results}

\section{Demonstration of Loss of $\mathbf{p 5 7}^{\mathrm{kip} 2}$ Expression by Immunohistochemistry}

Pancreatectomy specimens from patients with focal hyperinsulinism usually include a focus of endocrine cell adenomatous hyperplasia surrounded by normal pancreas (Figure 1a and b). This is to achieve clear surgical margins. Immunohistochemistry reaction with $\mathrm{p} 57^{\mathrm{kip} 2}$ antibody labeled islet cell nuclei within the area of normal pancreas (Figure 1c). Not all islet cell nuclei labeled strongly, which was expected because $p 57^{\text {kip2 }}$ is an inhibitor of G1 cyclin/cyclin-dependent kinase complexes, and its expression depends on the cell cycle stage in the individual cells. When there were moderately and strongly labeled endocrine cell nuclei in the islets of the normal portion of the pancreas, p5 $7^{\mathrm{kip} 2}$ reaction was interpreted as positive (' + ' in Table 1). A small number of the pancreatic duct epithelial cells and acinar cells showed moderate and strong nuclear labeling. Some of the foci of endocrine adenomatous hyperplasia had ill-defined borders and were interdigitating. Within such lesions, positively labeled duct epithelial cells and acinar cells were seen between the hyperplastic endocrine cells. In general, the labeling strength was in the moderate range rather than in the strong range in tissue sections that were previously frozen for the purpose of intraoperative analysis.

Out of 56 pancreatic specimens containing a focus of adenomatous hyperplasia, 48 showed clear loss of $\mathrm{p} 57^{\mathrm{kip} 2}$ expression within the lesion by immunohistochemistry (Table 1). Endocrine cells within the adenomatous foci lacked the $\mathrm{p} 57^{\mathrm{kip} 2}$ labeling that is seen in the islet cell nuclei of the normal surrounding pancreas from the same individual (' + ' in Table 1 and Figure 1c). The focal lesions and normal pancreas were present either on a single slide processed in a same cassette (43 specimens), or on separate slides which had been processed simultaneously (five specimens). When only previously frozen, pancreatic tissue used for intraoperative frozen section analysis was available for the adenomatous areas, normal pancreas was also chosen from the blocks of previously frozen tissue (frozen section controls). In the remaining eight pancreatic specimens (nos. 5, 6, 12, 22, 24, 34, 35, and 44), although the endocrine cells forming an adenomatous focus similarly did not display $\mathrm{p} 57^{\mathrm{kip} 2}$ nuclear labeling, the results were interpreted as not definitive for one of three reasons: (1) p57 ${ }^{\text {kip2 }}$ labeling in the normal areas was weak, as defined in the Materials and methods, possibly due to prior freezing, (2) there was only a narrow margin of normal tissue around the lesion, and only a small number of $\mathrm{p}^{\mathrm{kip} 2}$-positive islet cells were identified, and (3) the lesion itself was too small and crushed to conclude that the nuclei were negative for the p $57^{\text {kip2 }}$ reaction. 
Table $1 A B C C 8$ and $K C N J 11$ mutations, p57 $7^{\mathrm{kip} 2}$ expression in pancreatic tissue, and the result of microsatellite marker analysis of 56 patients with the labeling focal form of congenital hyperinsulinism

\begin{tabular}{|c|c|c|c|c|c|}
\hline \multirow{2}{*}{$\begin{array}{l}\text { Patient } \\
\text { no. }\end{array}$} & \multirow{2}{*}{$K_{A T P}$ mutations $^{\mathrm{a}}$} & \multicolumn{2}{|c|}{ Nuclear labeling of $p 57^{k i p 2}$} & \multirow{2}{*}{$\begin{array}{l}\text { Microsatellite marker } \\
\text { analysis at 11p15 }\end{array}$} & \multirow{2}{*}{ Remarks on histology } \\
\hline & & Lesion & $\begin{array}{l}\text { Islets in normal } \\
\text { area }\end{array}$ & & \\
\hline
\end{tabular}

\begin{tabular}{|c|c|c|c|c|c|}
\hline 1 & g3992-9a/- & - & + & ND & \\
\hline 2 & R1494Q/- & - & + & ND & \\
\hline 3 & V21D/- & - & + & ND & \\
\hline 4 & g3992-9a/- & - & + & ND & \\
\hline 5 & 3576 del g/- & $\begin{array}{l}\text { Small } \\
\text { lesion }\end{array}$ & + & ND & \\
\hline 6 & R74W/- & - & $\begin{array}{l}\text { Small normal area } \\
\text { and weak }\end{array}$ & Loss of maternal allele & \\
\hline 7 & C717X/- & - & + & Loss of maternal allele & \\
\hline 8 & $1874 \mathrm{del} \mathrm{c} /-$ & - & + & ND & \\
\hline 9 & Q954X/- & - & + & ND & \\
\hline 10 & g3992-9g/- & - & + & Loss of maternal allele & \\
\hline 11 & E501K/- & - & + & Loss of maternal allele & \\
\hline 12 & $\mathrm{R} 136 \mathrm{~L}^{\mathrm{b}} /-$ & - & Weak & Loss of maternal allele & \\
\hline 13 & c2924-9a/- & - & + & Loss of maternal allele & $\begin{array}{l}\text { Focal lesion occupies large area of } \\
\text { pancreas }\end{array}$ \\
\hline 14 & g3992-9a/- & - & + & ND & \\
\hline 15 & $3084 \mathrm{del}$ g/- & - & + & ND & \\
\hline 16 & $\mathrm{R} 302 \mathrm{H}^{\mathrm{b}} /-$ & - & + & Loss of maternal allele & \\
\hline 17 & g3992-9a/- & - & + & ND & \\
\hline 18 & $536-539 \mathrm{del}$ atgg $/-$ & - & + & ND & \\
\hline 19 & R1215W/- & - & + & Loss of maternal allele & \\
\hline 20 & R999X/- & - & + & ND & \\
\hline 21 & L1350Q/- & - & + & ND & \\
\hline 22 & G1401R/- & - & Weak & Loss of maternal allele & \\
\hline 23 & g2041-21a/- & - & + & Loss of maternal allele & \\
\hline 24 & G7R/- & - & Weak & Loss of maternal allele & \\
\hline 25 & g3992-9a/- & - & + & Loss of maternal allele & Rare nonadjacent large islet cell nuclei \\
\hline 26 & g3992-9a/- & - & + & ND & \\
\hline 27 & Q954X/- & - & + & ND & \\
\hline 28 & delF1388/- & - & + & ND & \\
\hline 29 & Q472X/- & - & + & ND & \\
\hline 30 & $\widehat{\mathrm{G}} 40 \mathrm{D}^{\mathrm{b}} /-$ & - & + & Loss of maternal allele & \\
\hline 31 & $\mathrm{~S} 116 \mathrm{P}^{\mathrm{b}} /-$ & - & + & ND & \\
\hline 32 & g3992-9a/- & - & + & ND & \\
\hline 33 & $\begin{array}{l}\text { g2116+1t, } \\
\text { nonmaternal }\end{array}$ & - & + & ND & \\
\hline 34 & $\begin{array}{l}\text { A101D } \\
\text { nonmaternal }\end{array}$ & - & Small normal area & Loss of maternal allele & $\begin{array}{l}\text { Focal lesion occupies large area of } \\
\text { pancreas }\end{array}$ \\
\hline 35 & F27S, nonmaternal & - & Weak & Loss of maternal allele & \\
\hline 36 & $\begin{array}{l}\text { G1379R, } \\
\text { nonmaternal }\end{array}$ & - & + & ND & \\
\hline 37 & $\begin{array}{l}1631 \text { del t, } \\
\text { nonmaternal }\end{array}$ & - & + & ND & \\
\hline 38 & $\begin{array}{l}\text { R1215W, } \\
\text { nonmaternal }\end{array}$ & - & + & Loss of maternal allele & \\
\hline 39 & $\begin{array}{l}\text { L503P, } \\
\text { nonmaternal }\end{array}$ & - & + & Loss of maternal allele & \\
\hline 40 & F686S, de novo & - & + & Loss of maternal allele & \\
\hline 41 & $\begin{array}{l}1332+4 \text { del c, } \\
\text { maternal }^{\mathrm{c}}\end{array}$ & - & + & Loss of maternal allele & \\
\hline 42 & $-1-$ & - & + & Loss of maternal allele & \\
\hline 43 & $-1-$ & - & + & ND & \\
\hline 44 & $-1-$ & $\begin{array}{l}\text { Small } \\
\text { lesion }\end{array}$ & + & Loss of maternal allele & \\
\hline 45 & $-1-$ & - & + & Loss of maternal allele & \\
\hline 46 & $-1-$ & - & + & Loss of maternal allele & \\
\hline 47 & $-1-$ & - & + & ND & \\
\hline 48 & $-1-$ & - & + & Loss of maternal allele & \\
\hline 49 & $-1-$ & - & + & ND & \\
\hline 50 & ND & - & + & ND & \\
\hline 51 & ND & - & + & ND & \\
\hline 52 & ND & - & + & Loss of maternal allele & Rare nonadjacent large islet cell nuclei \\
\hline 53 & ND & - & + & Loss of maternal allele & $\begin{array}{l}\text { Focal lesion occupies large area of } \\
\text { pancreas }\end{array}$ \\
\hline
\end{tabular}


Table 1 Continued

\begin{tabular}{|c|c|c|c|c|c|}
\hline \multirow{2}{*}{$\begin{array}{l}\text { Patient } \\
\text { no. }\end{array}$} & \multirow[t]{2}{*}{$K_{A T P}$ mutations ${ }^{\mathrm{a}}$} & \multicolumn{2}{|c|}{ Nuclear labeling of p57 $7^{\text {kip } 2}$} & \multirow{2}{*}{$\begin{array}{l}\text { Microsatellite marker } \\
\text { analysis at } 11 p 15\end{array}$} & \multirow[t]{2}{*}{ Remarks on histology } \\
\hline & & Lesion & $\begin{array}{l}\text { Islets in normal } \\
\text { area }\end{array}$ & & \\
\hline 54 & ND & - & + & ND & \\
\hline 55 & ND & - & + & ND & \\
\hline 56 & ND & - & + & Loss of maternal allele & \\
\hline
\end{tabular}

${ }^{\mathrm{a}}$ Nucleotide and codon positions of the ABCC8 mutations are according to the full-length human ABCC8 (SUR1) cDNA sequence incorporating the alternatively spliced form of exon 17 (Genebank Accession no. L78224). Codon positions of KCNJ11 mutations are according to the human KCNJ11 (Kir6.2) sequence (Genebank Accession no. D50582). The paternal mutations are listed on left of /, and the maternal on the right, when known.

${ }^{\mathrm{b}}$ KCNJ11 mutations.

${ }^{\mathrm{c}}$ See text for detail.

ND: test not done.

All 10 pancreatic specimens studied from patients with diffuse hyperinsulinism did not show loss of p57 ${ }^{\text {kip2 }}$ labeling of the islet cell nuclei (data not shown). Among them, five patients had $A B C C 8$ mutations and one had KCNJ11 mutations.

\section{Microsatellite Marker Analysis}

Haplotyping by microsatellite markers was performed in 27 cases of focal hyperinsulinism. Selective loss of the maternal $11 \mathrm{p}$ region was demonstrated in all focal lesions by significant decrease $(P<0.05)$ in maternal/paternal peak ratios of the PCR products amplified from the lesional tissue compared to those obtained from the normal pancreas or lymphocytes (Table 1). Peaks for one marker ( $A B C C 8$ intron 10) obtained from case no. 19 and other representative results are shown in Figure 2a and b, respectively.

Among these 27 patients were one with a de novo mutation (no. 40), five with no identifiable $\mathrm{K}_{\mathrm{ATP}}$ mutations (nos. 42, 44, 45, 46, and 48), and three without mutation analysis data (nos. 52, 53, and 56) (see also below). One patient with a maternally inherited $A B C C 8$ intronic single base deletion (no. 41) also showed maternal loss of the 11 p15 region (see Discussion).

\section{$\mathrm{K}_{\mathrm{ATP}}$ Mutation Analysis}

$\mathrm{K}_{\text {ATP }}$ mutation analysis was conducted in 49 patients. Thirty-two patients had either an $A B C C 8$ or a KCNJ11 mutation that was inherited from the father (Table 1). Seven other patients possessed mutations that were not from the mother, but paternal DNA material was not available. One individual (no. 40) was found to have an F686S point mutation which was not identified in either parent. This mutation is considered to have occurred de novo. No changes were detected in the coding and flanking regions of $A B C C 8$ and KCNJ11 in eight cases screened by conformation-sensitive gel electrophoresis. A nucleotide deletion $(1332+4$ del c) was identified in intron 8 of the maternal ABCC8 in patient no. 41. The deletion was initially detected by conformation-sensitive gel electrophoresis. These particular abnormal bands were not seen in 50 normoglycemic individuals by the same method (data not shown). Direct sequencing further confirmed the absence of the change in 25 normoglycemic individuals.

Five of the eight cases whose p5 $7^{\mathrm{kip} 2}$ immunohistochemical results were not definitive as described in the previous section had paternally inherited $A B C C 8$ mutations (nos. 5, 6, 22, and 24) or a KCNJ11 mutation (no. 12), and two others had nonmaternal mutations (nos. 34 and 35). The one remaining case had no identifiable coding region mutations (no. 44). Microsatellite marker analysis demonstrated loss of maternal 11p15 in the focal lesion of this patient (see above).

\section{Discussion}

Focal hyperinsulinism has been proposed to arise through a two-hit mechanism that includes loss of heterozygosity for the maternal chromosome 11p and reduction to hemizygosity of the paternally derived allele with $\mathrm{K}_{\text {АтP }}$ channel mutations. Since $\mathrm{K}_{\text {АтP }}$ mutations are not always identified in patients with histologically focal form of hyperinsulinism, we questioned whether all cases of focal hyperinsulinism result from the same mechanism. In order to answer this question, this study was conducted utilizing morphologic and molecular techniques.

In total, 56 pancreatic specimens were analyzed by immunohistochemistry for the $\mathrm{p} 57^{\mathrm{kip} 2}$ nuclear protein, which is imprinted with expression from the maternal allele. All but eight focal lesions demonstrated clear loss of p57 $7^{\text {kip2 }}$. Nevertheless, we were able to demonstrate that these eight cases without definitive $\mathrm{p} 57^{\mathrm{kip} 2}$ results had at least one strand of molecular evidence that the lesion arose through the same pathway. Loss of the 11 p15 region 
was directly documented by microsatellite marker analysis in seven of the eight cases with or without paternal $\mathrm{K}_{\mathrm{ATP}}$ mutations. For the one remaining patient (no. 5), the focal lesion was so small that no lesional tissue was left in the paraffin block to perform microsatellite marker analysis. This patient, however, did have a paternally inherited $\mathrm{K}_{\mathrm{ATP}}$ mutation.

Mutation analysis showed that one patient had a de novo $\mathrm{K}_{\mathrm{ATP}}$ mutation, that is, the mutation was not present in either parent's DNA. The focal lesion of this patient showed a clear loss of $\mathrm{p}^{\mathrm{kip} 2}$ labeling and loss of maternal 11p15 microsatellite markers. There were eight patients in whom we could not identify any $K_{\text {АтP }}$ coding and flanking region mutations. Seven of them showed a clear loss of p5 $7^{\text {kip } 2}$ expression, and five lesions (including one, no. 44 , with a crushed lesion too small to conclude a p5 $7^{\text {kip2 }}$ expression loss) demonstrated a significantly reduced peak of the maternal 11p15 markers. These data strongly support the contention that focal islet cell adenomatous proliferation is caused by loss of maternally imprinted genes, even in patients with de novo mutations and patients with no identifiable mutations.

One patient (no. 41) revealed to have a single base deletion in intron $8,4 \mathrm{bp} 3^{\prime}$ to the exon/intron junction. No other base changes were identified by direct sequencing of all exons. This single base deletion was initially considered a candidate for the disease-causing mutation as it could alter the splicing mechanism. However, immunohistochemistry for $\mathrm{p} 57^{\mathrm{kip} 2}$ and microsatellite marker analysis were both consistent with loss of the maternally derived 11p15, compatible with the usual mechanism for the focal form of congenital hyperinsulinism (ie, loss of the maternal allele, leading to exposure of a paternal disease-causing mutation). As this deletion in intron 8 was not identified in 50 normoglycemic individuals, it may represent a rare sequence variant of uncertain significance. This example is instructive in that results from two separate methods supplemented a result by a third, and the combination of all three modalities was necessary to interpret the alterations.

The sensitivity of conformation-sensitive gel electrophoresis to identify mutations is generally $90 \% .{ }^{30}$ As there was a small chance that some $\mathrm{K}_{\mathrm{ATP}}$ mutations escaped identification by this method, PCR products were subsequently directly sequenced for two of eight conformation-sensitive gel electrophoresis-negative patients, disclosing no mutations. Intronic mutations that can alter splicing may not be detected if they reside outside the PCR-amplified flanking region. Another possibility to be considered is that patients may have acquired a somatic mutation in the pancreatic endocrine cells during an earlier stage of development. In this scenario, there would still be a need for a second genetic event to lose a maternally derived allele in order to develop a focal lesion. Mutation analysis of the endocrine cells within the lesion would be necessary to test this hypothesis.

As indicated in Table 1, there were five focal lesions that had unusual histologic features. While the majority of foci of adenomatous hyperplasia are small and measure less than $1.0 \mathrm{~cm}$ in diameters, ${ }^{26}$ three lesions (nos. 13, 34, and 53) were large and occupied almost the entire pancreas. There were two other cases (nos. 25 and 52) in which rare large islet cell nuclei were present in the pancreas nonadjacent to the focus of adenomatous hyperplasia (focal lesion). However, because some focal lesions have ill-defined borders and proliferating endocrine cells extend processes into the adjacent normal pancreas, it is possible that the large islet cell nuclei in the nonadjacent pancreas are still part of the same lesion. Although the large nuclei thought to be 'outside' the lesion may, indeed, be part of the same lesion, we do not currently know the significance of these large nuclei. Similar cases have been observed in other series. ${ }^{17,28}$ Nevertheless, in all of the five focal hyperinsulinism cases with unusual histology, we demonstrated loss of the maternal $11 \mathrm{p} 15$ region by microsatellite marker analysis. Therefore, we infer that focal hyperinsulinism with some unusual histologic features are due to the proposed pathway.

In summary, all 56 focal hyperinsulinism patients and their pancreatic islet cell adenomatous lesions analyzed by immunohistochemical and molecular techniques showed at least one piece of evidence consistent with the proposed pathogenesis of the disease, that is, paternal $\mathrm{K}_{\mathrm{ATP}}$ mutation paired with maternal 11p15 loss. The results indicate that this is the predominant causative mechanism of the focal form of hyperinsulinism.

\section{Acknowledgements}

This work was supported, in part, by grants from the National Institutes of Health (RO1 DK 56268 to CAS and MO1 RR 00240). We thank Joanne Mauger for her excellent technical assistance. We also thank Andrea Matter, Nkecha Hughes, and the nursing and laboratory staff of The Children's Hospital of Philadelphia for their expert assistance.

\section{References}

1 Yakovac WC, Baker L, Hummeler K. Beta cell nesidioblastosis in idiopathic hypoglycemia of infancy. J Pediatr 1971;79:226-231.

2 Jaffe R, Hashida Y, Yunis EJ. Pancreatic pathology in hyperinsulinemic hypoglycemia of infancy. Lab Invest 1980;42:356-365.

3 Rahier J, Falt K, Muntefering $\mathrm{H}$, et al. The basic structural lesion of persistent neonatal hypoglycaemia with hyperinsulinism: deficiency of pancreatic D cells or hyperactivity of B cells? Diabetologia 1984;26: 282-289. 
4 Witte DP, Greider MH, DeSchryver-Kecskemeti K, et al. The juvenile human endocrine pancreas: normal $\mathrm{v}$ idiopathic hyperinsulinemic hypoglycemia. Semin Diagn Pathol 1984;1:30-42.

5 Glaser B, Thornton P, Otonkoski T, et al. Genetics of neonatal hyperinsulinism. Arch Dis Child Fetal Neonatal Ed 2000;82:F79-F86.

6 Glaser B, Kesavan P, Heyman M, et al. Familial hyperinsulinism caused by an activating glucokinase mutation. N Engl J Med 1998;338:226-230.

7 Stanley CA, Lieu YK, Hsu BY, et al. Hyperinsulinism and hyperammonemia in infants with regulatory mutations of the glutamate dehydrogenase gene. N Engl J Med 1998;338:1352-1357.

8 Clayton PT, Eaton S, Aynsley-Green A, et al. Hyperinsulinism in short-chain L-3-hydroxyacyl-CoA dehydrogenase deficiency reveals the importance of betaoxidation in insulin secretion. J Clin Invest 2001;108: 457-465.

9 Aguilar-Bryan L, Nichols CG, Wechsler SW, et al. Cloning of the beta cell high-affinity sulfonylurea receptor: a regulator of insulin secretion. Science 1995; 268:423-426.

10 Inagaki N, Gonoi T, Clement JPT, et al. Reconstitution of IKATP: an inward rectifier subunit plus the sulfonylurea receptor. Science 1995;270:1166-1170.

11 Goossens A, Gepts W, Saudubray JM, et al. Diffuse and focal nesidioblastosis. A clinicopathological study of 24 patients with persistent neonatal hyperinsulinemic hypoglycemia. Am J Surg Pathol 1989;13: 766-775.

12 Thomas PM, Cote GJ, Wohllk N, et al. Mutations in the sulfonylurea receptor gene in familial persistent hyperinsulinemic hypoglycemia of infancy. Science 1995;268:426-429.

13 Nestorowicz A, Inagaki N, Gonoi T, et al. A nonsense mutation in the inward rectifier potassium channel gene, Kir6.2, is associated with familial hyperinsulinism. Diabetes 1997;46:1743-1748.

14 Thomas P, Ye Y, Lightner E. Mutation of the pancreatic islet inward rectifier Kir6.2 also leads to familial persistent hyperinsulinemic hypoglycemia of infancy. Hum Mol Genet 1996;5:1809-1812.

15 Nestorowicz A, Wilson BA, Schoor KP, et al. Mutations in the sulfonylurea receptor gene are associated with familial hyperinsulinism in Ashkenazi Jews. Hum Mol Genet 1996;5:1813-1822.

16 Adzick NS, Thornton PS, Stanley CA, et al. A multidisciplinary approach to the focal form of congenital hyperinsulinism leads to successful treatment by partial pancreatectomy. J Pediatr Surg 2004;39: 270-275.

17 Suchi M, Thornton PS, Adzick NS, et al. Congenital hyperinsulinism: intraoperative biopsy interpretation can direct the extent of pancreatectomy. Am J Surg Pathol 2004;28:1326-1335.
18 de Lonlay P, Fournet JC, Rahier J, et al. Somatic deletion of the imprinted $11 \mathrm{p} 15$ region in sporadic persistent hyperinsulinemic hypoglycemia of infancy is specific of focal adenomatous hyperplasia and endorses partial pancreatectomy. J Clin Invest 1997; 100:802-807.

19 Verkarre V, Fournet JC, de Lonlay P, et al. Paternal mutation of the sulfonylurea receptor (SUR1) gene and maternal loss of 11p15 imprinted genes lead to persistent hyperinsulinism in focal adenomatous hyperplasia. J Clin Invest 1998;102:1286-1291.

20 Rainier S, Johnson LA, Dobry CJ, et al. Relaxation of imprinted genes in human cancer. Nature 1993;362: 747-749.

21 Ogawa O, Eccles MR, Szeto J, et al. Relaxation of insulin-like growth factor II gene imprinting implicated in Wilms' tumour. Nature 1993;362:749-751.

22 Matsuoka S, Thompson JS, Edwards MC, et al. Imprinting of the gene encoding a human cyclindependent kinase inhibitor, p57KIP2, on chromosome 11p15. Proc Natl Acad Sci USA 1996;93:3026-3030.

23 Lee MH, Reynisdottir I, Massague J. Cloning of p57KIP2, a cyclin-dependent kinase inhibitor with unique domain structure and tissue distribution. Genes Dev 1995;9:639-649.

24 Matsuoka S, Edwards MC, Bai C, et al. p57KIP2, a structurally distinct member of the p21CIP1 Cdk inhibitor family, is a candidate tumor suppressor gene. Genes Dev 1995;9:650-662.

25 Kassem SA, Ariel I, Thornton PS, et al. p57(KIP2) expression in normal islet cells and in hyperinsulinism of infancy. Diabetes 2001;50:2763-2769.

26 Stanley CA, Thornton PS, Ganguly A, et al. Preoperative evaluation of infants with focal or diffuse congenital hyperinsulinism by intraoperative acute insulin response tests and selective pancreatic arterial calcium stimulation. J Clin Endocrinol Metab 2004; 89:288-296.

27 Kassem SA, Ariel I, Thornton PS, et al. Beta-cell proliferation and apoptosis in the developing normal human pancreas and in hyperinsulinism of infancy. Diabetes 2000;49:1325-1333.

28 Suchi M, MacMullen C, Thornton PS, et al. Histopathology of congenital hyperinsulinism: retrospective study with genotype correlations. Pediatr Dev Pathol 2003;6:322-333.

29 Ganguly A, Rock MJ, Prockop DJ. Conformationsensitive gel electrophoresis for rapid detection of single-base differences in double-stranded PCR products and DNA fragments: evidence for solventinduced bends in DNA heteroduplexes. Proc Natl Acad Sci USA 1993;90:10325-10329.

30 Korkko J, Kaitila I, Lonnqvist L, et al. Sensitivity of conformation sensitive gel electrophoresis in detecting mutations in Marfan syndrome and related conditions. J Med Genet 2002;39:34-41. 